\title{
Effect of Contamination by Cleaning Agents and Hemostatic Agent on Dentin Bond Strength
}

\author{
Ezgi Sonkaya1', Gonca Zeliha Bek Kürklü²
}

${ }^{1,2}$ Department of Restorative Dentistry, Cukurova University, Turkey.

\section{ABSTRACT}

\section{BACKGROUND}

Contamination by hemostatic agent and rinsing with different disinfectant solutions can influence on micro shear bond strength between dentin and resin composite. The major objective of this study was to investigate the micro shear bond strengths of an etch and rinse technique and self-etch technique to human dentin contaminated with a hemostatic agent containing $\mathrm{AlCl}_{3}$ followed by chlorhexidine (CHX) and boric acid cleaning.

\section{METHODS}

A 50 non-carious, permanent, third molar teeth were randomly divided into five groups ( $\mathrm{N}=10$ per group); Group 1: Self etch technique (OptiBond All - In - One, Kerr) was used on dentin contaminated with hemostatic agent (Alustat, Cerkamed). Group 2: Etch and rinse technique (Phosphoric acid then OptiBond Universal, Kerr) was used. Group 3: Contaminated dentin was cleaned with CHX for 60 seconds and then self-etch technique was used. Group 4: Contaminated dentin was cleaned with boric acid for 60 seconds and then self-etch technique was used. Group 5: Hemostatic agent was not applied, only self-etch technique was used. Flat occlusal dentin surfaces were prepared and then restored with resin composite rod (Herculite Classic, Kerr) (1 mm diameter $\times 1 \mathrm{~mm}$ height). After thermocycling (1,000 cycles), composite sticks were subjected to microshear until fracture occurred at a crosshead speed of $0.5 \mathrm{~mm} / \mathrm{min}$. Statistical analysis was made with one-way analysis of variance (ANOVA) and multiple comparison tests with Tukey.

\section{RESULTS}

The mean microshear bond strength values of group 1 to group 5 were $21.89 \pm 12.43$, $26.15 \pm 22.79,20.05 \pm 12.03,35.08 \pm 13.20$ and $19.41 \pm 6.53 \mathrm{MPa}$, respectively. When the values of the groups were compared, the difference was not significant. $(\mathrm{P}=$ 0.108).

\section{CONCLUSIONS}

Boric acid and CHX may be used as alternatives to other materials that are used as cavity disinfectants on contaminated dentin by hemostatic agent.

\section{KEY WORDS}

Boric Acid, CHX, Hemostatic Agent, Adhesive Systems, Shear Bond Strength
Corresponding Author:

Dr. Ezgi Sonkaya,

Faculty of Dentistry,

Department of Restorative Dentistry,

Cukurova University, Adana, Turkey.

E-mail: sonkayaezgi@yahoo.com

DOI: $10.14260 /$ jemds/2021/635

How to Cite This Article:

Sonkaya E, Kürklü GZB. Effect of contamination by cleaning agents and haemostatic agent on dentin bond strength. J Evolution Med Dent Sci 2021;10(36): 3115-3120, DOI:

10.14260/jemds/2021/635

Submission 04-06-2021,

Peer Review 28-07-2021,

Acceptance 06-08-2021,

Published 06-09-2021.

Copyright (C) 2021 Ezgi Sonkaya et al. This is an open access article distributed under Creative Commons Attribution License [Attribution 4.0 International (CC BY 4.0)] 


\section{BACKGROUND}

The success of the bond strength between dentin and composite restoration can be affected by the stability of the hybrid layer. ${ }^{1}$ The deterioration in the hybrid layer can develop in 3 ways. First, collagen fibrils which are exposed during etching and rinse may degenerate. ${ }^{2}$ In the second place, demineralized collagen fibrils restrict resin infiltration by collapsing due to hydrogen bonds between peptides, as they are air-dried during bonding.3,4 Third, fluid movement within the dentinal tubules due to pulpal pressure causes insufficient leakage of the monomers in the resin into the dentin tubules. ${ }^{5}$ Hence, inadequate binding occurs internally between dentin and adhesive. ${ }^{6}$ In addition to all of these, failures increase even more because of contamination of prepared dentin with internal agents such as saliva, gingival fluids, blood, or external agents such as lubricants from the aerator and hemostatic agents. ${ }^{7}$

Hemostatic agent, which is used to stop bleeding coming from gingival inflammation or gingival trauma from tooth preparation and decreased gingival fluids, have a deleterious effect on bond strength between adhesive and dentine. ${ }^{8}$ These materials have high acidity and include aluminum chloride or aluminum sulfate or ferric sulfate. ${ }^{9}$ According to the studies in the literature, 20 - $25 \%$ aluminum chloride agents are used, and they have been observed to show the cytotoxic effect on gingival fibroblast cells at $48 \mathrm{~h}-72 \mathrm{~h}$ time points and lead to demineralization of dentin.9,10 Therefore, these hemostatic agent residues need to be removed from the dentin surface to which the bonding will be made. This led to the idea of cleaning the dentin surface with various cleaning agents.

As a cleaning agent chlorhexidine (CHX) is widely used.11 In addition to its antimicrobial effects, researchers have shown that chlorhexidine acts as an MMP inhibitor and limited the collagen breakdown in the hybrid layer. ${ }^{11}$ In this way, it is thought that the connection between dentin and adhesive will not be disrupted and at the same time, the fibrillar structure of the collagen matrix can contribute to the remineralization of dentin as the fibrillar structure is preserved. ${ }^{12}$ Due to the bactericidal, fungicide, and antiseptic properties of boric acid, the idea of it being used as a cavity disinfectant has come up. It is a weak inorganic acid form of boron element.13 Furthermore, when used in the treatment of periodontal diseases, a positive response was observed from some clinical measurements such as alveolar bone loss and bleeding on probing. ${ }^{14}$

There are studies showing that the connections of self-etch adhesive systems are adversely affected due to changes in the smear layer because of hemostatic agent contaminations. ${ }^{15,16}$

Most studies on this subject have focused on the effects of cleaning with CHX.2,17 There has been little quantitative analysis of how different cavity disinfectants affect dentin bond strength. The major objective of this study was to investigate the micro shear bond strengths of an etch and rinse technique and self-etch technique to human dentin contaminated with a hemostatic agent containing $\mathrm{AlCl}_{3}$ followed by CHX and boric acid cleaning. Our null hypothesis was that cleaning the dentin with CHX and boric acid after hemostatic agent was applied and performing thermal cycles did not affect the bond strength.

\section{METHODS}

50 non-carious, permanent, intact, extracted, third lower human molar teeth were gathered by the Non-Invasive Clinical Research Ethics Committee of Cukurova University Faculty of Medicine, dated 21. 05. 2021, numbered 43. The procedures used in this study adhere to the tenets of the Declaration of Helsinki. Our study is an in-vitro study and was conducted between June 2020 and January 2021. To expose flat dentin surfaces, the occlusal enamel of each tooth was trimmed horizontally using carbon separator under water coolant. To obtain a homogeneous dentin surface, the exposed dentin surface was sanded with 600 and 1200 grit water sandpaper $\mathrm{SiC}$ for 60 seconds. Then, the teeth were randomly separated into five groups $(\mathrm{n}=10) .{ }^{18}$ Cotton pellets impregnated with hemostatic agent (Alustat, Cerkamed, Stalowa Wola, Poland) were applied to all dentin surfaces except group 5 for 90 seconds. Then the tooth surface was washed with air - water spray for 15 seconds and dried with the help of oil free air for 5 seconds. Subsequently, the treatment protocol was applied for the subgroups -

- $\quad$ Group 1 - Self-etch technique was used. Applied self-etch adhesive OptiBond All-In-One (Kerr Corporation, Orange, CA, USA). It was scrubbed continuously on the dentin surface for $20 \mathrm{~s}$ by brush, air - thin for $5 \mathrm{~s}$ and light cured for $10 \mathrm{~s}$ (LED - Elipar Freelight, 3M - ESPE, USA).

- Group 2 - Etch and rinse technique was used. Dentin was etched with $37.5 \%$ phosphoric acid (Kerr Gel Etchant, Kerr, Orange, CA, USA) for $15 \mathrm{~s}$ and rinsed with water for $15 \mathrm{~s}$. The surface was left wet and excess water was removed by blotting with a tissue paper, leaving the surface visibly moist. And then OptiBond Universal was applied. It was scrubbed continuously on the dentin surface for $20 \mathrm{~s}$ by brush, air - thin for $5 \mathrm{~s}$ and light cured for $10 \mathrm{~s}$.

- Group 3 - Cleaning with CHX for 60 seconds and dried with absorbent and then OptiBond All-In-One was applied. It was scrubbed continuously on the dentin surface for $20 \mathrm{~s}$ by brush, air - thin for $5 \mathrm{~s}$ and light cured for $10 \mathrm{~s}$.

- Group 4 - Cleaning with boric acid for 60 seconds and dried with absorbent and then OptiBond All-In-One was applied. It was scrubbed continuously on the dentin surface for $20 \mathrm{~s}$ by brush, air - thin for $5 \mathrm{~s}$ and light cured for $10 \mathrm{~s}$.

- Group 5 - Hemostatic agent was not applied. Only selfetch technique used. Applied self-etch adhesive OptiBond All-In-One. It was scrubbed continuously on the dentin surface for $20 \mathrm{~s}$ by brush, air - thin for $5 \mathrm{~s}$ and light cured for $10 \mathrm{~s}$. The manufacturer and composition of materials used are presented in Table 1.

At the end of all treatment procedures for the build up of the composite micro cylinders, used starch tubes (Nuh'un Ankara Makarnası, Ankara, Turkey) of 1 millimeter (mm) internal diameter and $1 \mathrm{~mm}$ height were used for placing the composite (Herculite Classic, Kerr, Orange, CA, USA). LED Elipar Freelight (3M - ESPE, USA) was used for the polymerization of the samples. It was polymerized for 20 seconds according to the manufacturer's instructions. 
They were submerged in $37{ }^{\circ} \mathrm{C}$ distilled water for $24 \mathrm{~h}$. Prior to testing, the specimens were subjected to thermocycling for 1,000 cycles in water $\left(5 / 55^{\circ} \mathrm{C}\right)$ with 30 seconds of dwell time and 30 seconds of transfer time. ${ }^{17}$ Finally, the micro shear bond strength ( $\mu$-SBS) was measured using an universal testing machine (MOD Dental MIC - 101, Esetron Smart Robototechnologies, Ankara, Turkey) at a crosshead speed of $0.5 \mathrm{~mm} /$ minute until failure occurred. The $\mu$ - SBS values were calculated in mega Pascal (MPa).

\begin{tabular}{|c|c|c|}
\hline Material & Composition & Manufacturer \\
\hline $\begin{array}{l}\text { OptiBond All - In - } \\
\text { One }\end{array}$ & $\begin{array}{l}\text { Acetone, ethyl alcohol, TEGDMA, mineral } \\
\text { fillers, ytterbium fluoride, photoinitiators, } \\
\text { accelerators, stabilizers, water }\end{array}$ & $\begin{array}{l}\text { Kerr Corporation, } \\
\text { Orange, CA, USA }\end{array}$ \\
\hline OptiBond Universal & $\begin{array}{c}\text { Acetone, } 2 \text { - hydroxyethyl methacrylate, } \\
\text { glycerol dimethacrylate, ethanol, glycerol } \\
\text { phosphate dimethacrylate }\end{array}$ & $\begin{array}{l}\text { Kerr Corporation, } \\
\text { Orange, CA, USA }\end{array}$ \\
\hline $\begin{array}{l}\text { Herculite Classic } \\
\text { Composite }\end{array}$ & $\begin{array}{l}\text { Bis - GMA, TEGDMA, Borosilicate - } \\
\text { aluminum glass }\end{array}$ & $\begin{array}{l}\text { Kerr Corporation, } \\
\text { Orange, CA, USA }\end{array}$ \\
\hline Gel etching & $37,5 \%$ phosphoric acid & $\begin{array}{l}\text { Kerr Corporation, } \\
\text { Orange, CA, USA }\end{array}$ \\
\hline $\begin{array}{c}\text { Chlorhexidine } \\
\text { Antibacterial Solution }\end{array}$ & $\begin{array}{l}2 \% \text { chlorhexidine gluconate containing } \\
\text { disinfectant }\end{array}$ & $\begin{array}{l}\text { Consepsis } \\
\text { Ultradent, South } \\
\text { Jordan, UT, USA }\end{array}$ \\
\hline $5 \%$ Boric acid & Boric asit, distilled water & Handmade \\
\hline Hemosta & Alumi & $\begin{array}{l}\text { Alustat, Cerkamed, } \\
\text { Poland }\end{array}$ \\
\hline \multicolumn{3}{|c|}{ Table 1. Materials Used in the Study } \\
\hline
\end{tabular}

$\mu-\mathrm{SBS}=\mathrm{P} / \boldsymbol{\pi r} 2, \mathrm{P}=$ load at failure (in newton), $\boldsymbol{\pi}=3.14$, and $r=$ radius of restorative material microcylinder (in $\mathrm{mm}$ ).

After measuring, each fractured specimen was evaluated using a stereomicroscope (SOIF optical instruments, ST6024 B2, İstanbul, Turkey) at $40 \times$ magnification to make out its mode of failure. The failure mode was defined into the following types: ${ }^{18,19}$

- Type I - Adhesive failure (failure at the interface between dentin and restorative material)

- Type II - Cohesive failure (failure in the restorative material)
- $\quad$ Type III - Mixed failure (involving both adhesive and cohesive failures)

\section{Statistical Analysis}

Statistical analysis was made with one-way analysis of variance (ANOVA) and multiple comparison tests with Tukey. All statistical analyses were conducted at a significance level of $\mathrm{P}<0.05$.

\section{RESULTS}

Mean and standard deviation values are summarized in Table 2 . When the mean \pm standard deviation of micro shear bond strength values of the groups were compared, the difference between the groups was not significant $(\mathrm{P}=0.108)$.

\begin{tabular}{|c|c|c|}
\hline & $\mathbf{N}$ & Mean \pm Standard Deviation \\
\hline Group 1 & 10 & $21.89 \pm 12.43^{a}$ \\
\hline Group 2 & 10 & $26.15 \pm 22.79 a$ \\
\hline Group 3 & 10 & $20.05 \pm 12.03$ \\
\hline Group 4 & 10 & $35.08 \pm 13.20^{a}$ \\
\hline Group 5 & 10 & $19.41 \pm 6.53$ a \\
\hline P Value & & 0.108 \\
\hline \multicolumn{3}{|c|}{$\begin{array}{c}\text { Table 2. Mean } \pm \text { Standard Deviation of Micro Shear Bond Strength } \\
\text { (in MPa) of the Tested Groups }\end{array}$} \\
\hline
\end{tabular}

The percentages of the fracture modes observed with all tested groups are presented in Figure 1. There is no significant difference between the percentages of failure modes according to the groups $(\mathrm{P}=0.610)$. In all tested groups, predominant mode of failure was adhesive.

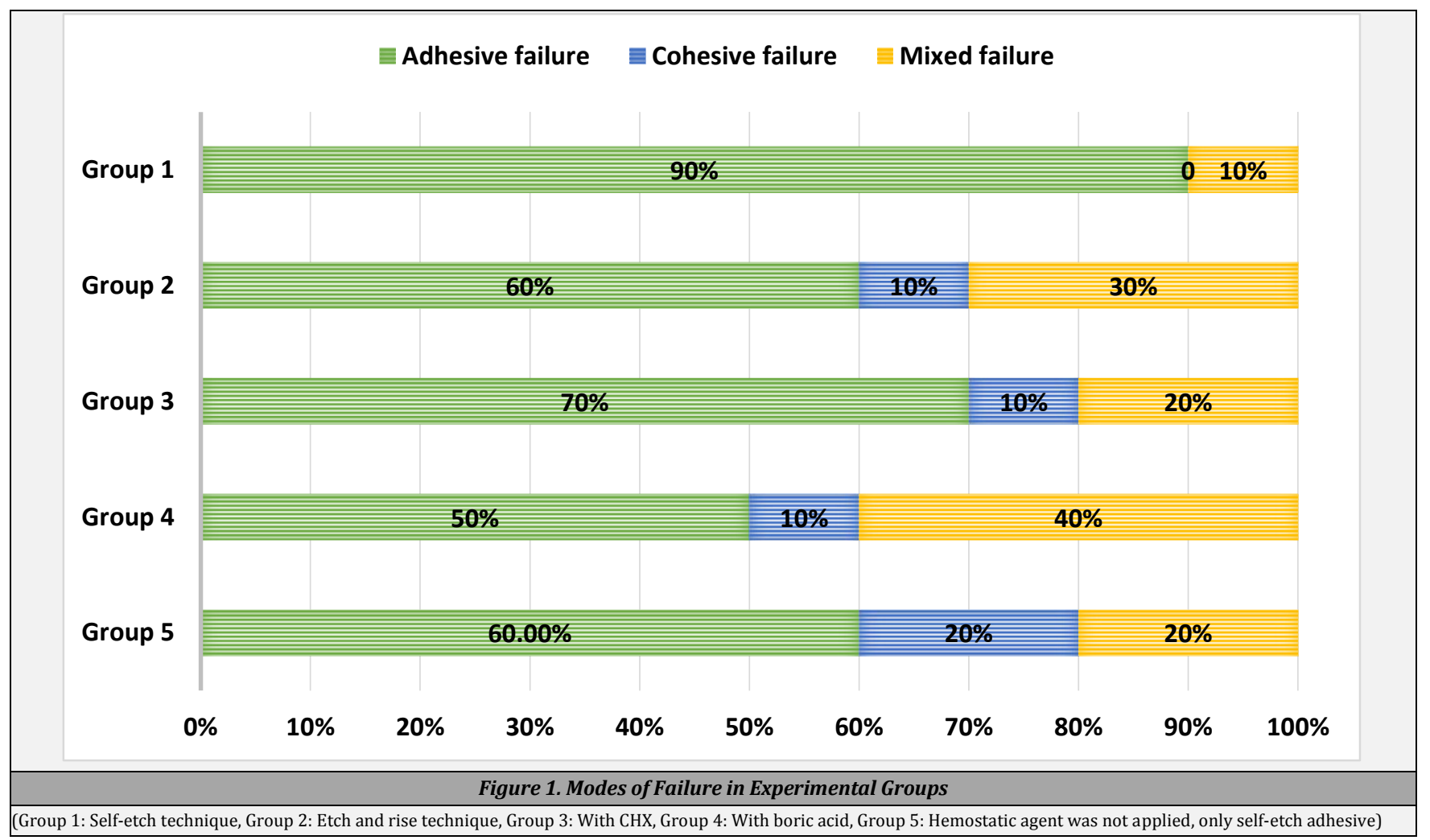




\section{DISCUSSION}

Hemostatic agent, which is containing $\mathrm{AlO}_{3}$ and having an acidic $\mathrm{pH}$ in the range of 0.7 to $3^{20}$ might affect the smear layer on the dentin surface and indirectly the bond strength. The dental adhesives are used specifically to bond composites, but their ability to reach dentin tubules and modify smear layer may be hampered by contaminated dentin surface. Therefore, it has been suggested to use various cleansing agents such as $\mathrm{CHX}$ and boric acid. This study evaluated the effect of different cleaning protocols on the shear bond strength of a universal adhesive to dentin contaminated with a hemostatic agent. The null hypothesis is not rejected. In the present study, the boric acid group and CHX did not show significant differences among the other methods used. Using etch and rinse technique with universal adhesive had higher $\mu$ - SBS than other groups but it was also not showing statistically significant difference among other groups.

There was no statistical difference in the micro shear values between the self-etch groups applied with a hemostatic agent $(\mathrm{P} \leq 0.05)$. Although there are concerns that hemostat may affect the bonding strength of agents containing ferric sulfate and aluminum chloride, this result may be because washing with water removes the hemostatic agent sufficiently. Harnirattisai et al. (2009) used a hemostatic agent containing $25 \%$ aluminum chloride in their study. They stated that due to the acidity of the hemostatic, it created a demineralization effect on the dentin surface, but this did not affect the bonding strength of adhesives. ${ }^{21}$ Our study corresponded to these results. There are studies that did not support this view. Kuphasuk et al. in their study found that the solution containing $25 \% \mathrm{AlCl}_{3}$ showed lower bonding value in the used self-etching adhesive groups in the contaminated dentin compared to the normal dentin. ${ }^{16}$ Ünlü et al. (2010) and Cebe and Çobanoğlu (2014), showed that hemostatic agent application had a negative effect on the bonding performance of self-etch adhesives. ${ }^{19,22}$ Ünlü et al. ${ }^{19}$ applied different hemostatic agents for 2 minutes to dentine contaminated with blood. They stated that the primers of the bonds they used were light (CSE) and medium acidity (ACE, ASEP) and because no extra washing was done, coagulating agents could not be removed sufficiently, and the bonding strength was reduced because of an insufficient hybrid layer. In addition, the selfetch systems used in these two studies contained water as a solvent in their primers. ${ }^{19,22}$ The bonds we used in our study, Optibond All-In-One contained water + ethanol + acetone as a solvent and Optibond Universal contained water + ethanol as a solvent. $\mathrm{AlCl}_{3}$ can dissolve in organic solvents such as water, acetone, and ethanol.23 One of the reasons for not having a statistically significant difference between the groups may be that the bond content we used was different from other studies. In this research, we chose the Alustat hemostatic agent containing $25 \% \mathrm{AlCl}_{3}$ because we frequently used it in clinical practice. Since 90 seconds of application is sufficient to control bleeding in the soft tissues, (it is written recommended contact time up to 5 minutes by manufacturer in the instructions for use) we used this application time to our samples. However, the reason for not having a statistical difference in the group without hemostatic application may be the low demineralization of the dentin surface due to the short application time of the hemostatic agent. Previous studies have shown that contamination times longer than 4 minutes caused demineralization supported by SEM images. ${ }^{20,24}$

Dentin - composite bonding occurs with the hybrid layer formed by the access of the bonding agent to the collagen fibrils by modifying the smear layer in self-etch bonding systems. ${ }^{25}$ The self-etch system we used had a mild acidity ( $\mathrm{pH}$ $\geq 2.5$ ). Mild acidity may be insufficient to modify smear layer and contamination on dentin. Hence the hemostatic agent could not be removed sufficiently in the group 5 wherein no additional washing process was applied, the intended thickness of the hybrid layer may not have been formed and the bonding strength may have decreased compared to the other groups. Chlorhexidine is an antimicrobial cationic detergent. It can be used in more than one step in dental procedures. CHX can be used for cleaning the tooth surface before etching. ${ }^{26}$ or can be used to reduce the collagenolytic activity in dentin after etching. ${ }^{27}$ In the present research, we applied before etching. Some researchers showed higher bond strength values, ${ }^{28-30}$ while some showed that it did not affect the bonding statistically. ${ }^{31-34}$ In our study, we determined that CHX could be used as a surface disinfectant and did not affect bonding. Boric acid, which has bacteriostatic agent, antiinflammatory, osteoblastic activity, is versus with CHX, which has been accepted as the gold standard in cavity disinfection in recent years. In our study, $5 \%$ CHX concentration was used as a cavity disinfectant. Although it did not show statistically significant difference from other groups, it showed the highest bonding value between groups.

In addition, it is possible to talk about the limited effect of boric acid $\mathrm{pH}^{5,1}$ on dentin structure. ${ }^{35}$ Ercan et al. found that the self-etch adhesive systems were not statistically different from the control group in their bond strength after cleaning the cavity with $5 \%$ boric acid. ${ }^{36}$ Also, Aktürk et al. found that the bond strength of self-etch and universal adhesive systems was not affected after disinfection with $5 \%$ boric acid. ${ }^{37}$ Our study corresponded with other results. Moreover, boric acid has the ability to dissolve in ethanol and acetone. ${ }^{38}$ The adhesive we applied also contained acetone and ethanol, so using boric acid as a cavity disinfectant may not affect the bonding strength. Therefore, the antibacterial effect of boron can make boric acid a suitable alternative only as a cavity disinfectant. Boric acid group showed the highest $\mu$ - SBS. It was followed by a $37 \%$ phosphoric acid applied universal bond group using the etch and rinse method. Kuphasuk et al. found that when phosphoric acid was applied with the total etch technique in dentin contaminated with $25 \%$ aluminum chloride solution, it did not show statistically significant different $\mu$ - SBS values. ${ }^{16}$ In another study, the bonding strength values of the control group and the contamination groups were similar. ${ }^{19}$ It may be that $37 \%$ phosphoric acid, which has a very strong acidity, completely removes all hemostatic agents affected by contamination owing to its pronounced etching effect. ${ }^{39}$ Etching enamel with phosphoric acid also increases bonding. Bonding in dentin is more difficult than enamel due to its high organic matrix, water content and its heterogeneous structure that includes dentin canals, collagen fibers, hydroxyapatite crystals, and odontoblast extensions. ${ }^{40}$ This may be another reason why our results do not show significant differences.

Shear or tensile bond strength tests are among the most frequently preferred test methods to evaluate the performance of adhesive systems in the laboratory. It is 
believed that shear stresses contribute the most to the breakdown of adhesion of restorative materials in vivo. ${ }^{41}$ Therefore, we used the shear bond strength test to predict the clinical performance of the materials. Considering the limitations of this in vitro study is that the dentin surface is not contaminated with saliva and fresh blood. However, in clinical practice, there is not always blood and saliva contamination into the cavity, but the bleeding stopper may touch the cavity due to the application of the bleeding stopper with cotton pellet.

\section{CONCLUSIONS}

After the dentin is contaminated by hemostatic agent for a short time, it is easily removed with water. Contamination with hemostatic agent did not reduce the shear bond strength of both etch and rinse and self-etch adhesive systems. Application of chlorhexidine and boric acid after the removal of hemostatic agent did not affect the bond strength. Boric acid and CHX can be used as cavity disinfectants when dentin is contaminated by hemostatic agent.

Data sharing statement provided by the authors is available with the full text of this article at jemds.com.

Financial or other competing interests: None.

Disclosure forms provided by the authors are available with the full text of this article at jemds.com.

\section{REFERENCES}

[1] Nakabayashi N. The hybrid layer: a resin-dentin composite. Proc Finn Dent Soc 1992;88(Suppl 1):321-9.

[2] Carrilho MRO, Geraldeli S, Tay F, et al. In vivo preservation of the hybrid layer by chlorhexidine. J Dent Res 2007;86(6):529-33.

[3] Pashley DH, Tay FR, Carvalho RM, et al. From dry bonding to water-wet bonding to ethanol-wet bonding. A review of the interactions between dentin matrix and solvated resins using a macromodel of the hybrid layer. Am J Dent 2007;20(1):7-20.

[4] Mai S, Kim YK, Toledano M, et al. Phosphoric acid esters cannot replace polyvinylphosphonic acid as phosphoprotein analogs in biomimetic remineralization of resin-bonded dentin. Dent Mater 2009;25(10):1230-9.

[5] Hashimoto M. A review-micromorphological evidence of degradation in resin-dentin bonds and potential preventional solutions. J Biomed Mater Res B Appl Biomater 2010;92(1):268-80.

[6] Breschi L, Mazzoni A, Ruggeri A, et al. Dental adhesion review: aging and stability of the bonded interface. Dent Mater 200;24(1):90-101.

[7] Mohammadi N, Kimyai S, Bahari $M$, et al. Effect of aluminum chloride hemostatic agent on microleakage of class $\mathrm{V}$ composite resin restorations bonded with all-inone adhesive. Med Oral Patol Oral Cir Bucal 201;17(5):e841-4.

[8] Kaneshima T, Yatani H, Kasai T, et al. The influence of blood contamination on bond strengths between dentin and an adhesive resin cement. Oper Dent 2000;25(3):195-201.
[9] Land MF, Rosenstiel SF, Sandrik JL. Disturbance of the dentinal smear layer by acidic hemostatic agents. J Prosthet Dent 1994;72(1):4-7.

[10] Phumpatrakom P, Ariyakriangkai W, Srisuwan T, et al. In vitro cytotoxicity of some hemostatic agents used in apicoectomy to human periodontal ligament and bone cells. Saudi Endodontic Journal 2020;10(1):21-7.

[11] Kim J, Vaughn RM, Gu L, et al. Imperfect hybrid layers created by an aggressive one-step self-etch adhesive in primary dentin are amendable to biomimetic remineralization in vitro. J Biomed Mater Res A 2010;93(4):1225-34

[12] Maske TT, Kuper NK, Cenci MS, et al. Chlorhexidine, a matrix metalloproteinase inhibitor and the development of secondary caries wall lesions in a microcosm biofilm model. Caries Res 2019;53(1):107-17.

[13] Cangul S, Susgun Yildirim Z, Bahsi E, et al. Do ozone and boric acid affect microleakage in class $\mathrm{V}$ composite restorations? Ozone Science and Engineering 2019;41(1):92-101.

[14] Demirer S, Kara MI, Erciyas K, et al. Effects of boric acid on experimental periodontitis and alveolar bone loss in rats. Arch Oral Biol 2012;57(1):60-5.

[15] O'Keefe KL, Pinzon LM, Rivera B, et al. Bond strength of composite to astringent-contaminated dentin using selfetching adhesives. Am J Dent 2005;18(3):168-72.

[16] Kuphasuk W, Harnirattisai C, Senawongse P, et al. Bond strengths of two adhesive systems to dentin contaminated with a hemostatic agent. Oper Dent 2007;32(4):399-405.

[17] Hebling J, Pashley DH, Tjäderhane L, et al. Chlorhexidine arrests subclinical degradation of dentin hybrid layers in vivo. J Dent Res 2005;84(8):741-6.

[18] Armstrong S, Breschi L, Özcan M, et al. Academy of dental materials guidance on in vitro testing of dental composite bonding effectiveness to dentin/enamel using microtensile bond strength ( $\mu$ TBS) approach. Dent Mater 2017;33(2):133-43.

[19] Ünlü N, Çetin AR, Cebe MA, et al. Comparison of micro tensile bond strength of different adhesive systems to dentin contaminated with haemostatic agents. Hacettepe Dișhek Fak Derg 2010;34:3-4.

[20] Moosavi H, Mohammadipour HS, Ghavamnasiri M, et al. Effect of bleaching and thermocycling on resin-enamel bond strength. Int J Biomater 2015;2015:921425.

[21] Harnirattisai C, Kuphasuk W, Senawongse P, et al. Bond strengths of resin cements to astringent-contaminated dentin. Oper Dent 2009;34(4):415-22.

[22] Fatma CE, Çobanoğlu N. The effect of pulp perforation and a hemostatic agent on bonding strength to dentin of a selfetch adhesive system. Acta Odontologica Turcica 2014;31(1):23-30.

[23] Emons HH, Janneck E, Pollmer K. Studies on systems of salts and mixed solvents. XXVI. Solubility and solvation behaviour of aluminium (III) chloride in mixed aqueous organic solvents. Zeitschrift Für Anorganische und Allgemeine Chemie 1984;511(4):135-47.

[24] Land MF, Couri CC, Johnston WM. Smear layer instability caused by hemostatic agents. J Prosthet Dent 1996;76(5):477-82. 
[25] Moszner N, Salz U, Zimmermann J. Chemical aspects of self-etching enamel-dentin adhesives: a systematic review. Dent Mater 2005;21(10):895-910.

[26] Flury S, Peutzfeldt A, Schmidlin PR, et al. Exposed dentin: influence of cleaning procedures and simulated pulpal pressure on bond strength of a universal adhesive system. PLoS One 2017;12(1):e0169680.

[27] Alaghehmad H, Mansouri E, Esmaili B, et al. Effect of 0.12 $\%$ chlorhexidine and zinc nanoparticles on the microshear bond strength of dentin with a fifthgeneration adhesive. Eur J Dent 2018;12(1):105-10.

[28] Komori PC, Pashley DH, Tjäderhane L, et al. Effect of $2 \%$ chlorhexidine digluconate on the bond strength to normal versus caries affected dentin. Oper Dent 2009;34(2):15765.

[29] Loguercio AD, Stanislawczuk R, Polli LG, et al. Influence of chlorhexidine digluconate concentration and application time on resin-dentin bond strength durability. Eur J Oral Sci 2009;117(5):587-96.

[30] Breschi L, Cammelli F, Visintini E, et al. Influence of chlorhexidine concentration on the durability of etchand-rinse dentin bonds: a 12-month in vitro study. J Adhes Dent 2009;11(3):191-8.

[31] Aykut-Yetkiner A, Candan U, Ersin N, et al. Effect of $2 \%$ chlorhexidine gluconate cavity disinfectant on microtensile bond strength of tooth-coloured restorative materials to sound and caries-affected dentin. Journal of Adhesion Science and Technology 2015;29(12):1169-77.

[32] Bocangel JS, Kraul AO, Vargas AG, et al. Influence of disinfectant solutions on the tensile bond strength of a fourth generation dentin bonding agent. Pesquisa Odontológica Brasileira 2000;14(2):107-11.

[33] De-Melo MAS, Da Costa Goes D, De-Moraes MDR, et al. Effect of chlorhexidine on the bond strength of a self-etch adhesive system to sound and demineralized dentin. Braz Oral Res 2013;27(3):218-24.

[34] Mobarak EH. Effect of chlorhexidine pretreatment on bond strength durability of caries-affected dentin over 2year aging in artificial saliva and under simulated intrapulpal pressure. Oper Dent 2011;36(6):649-60.

[35] Prentice LH, Tyas MJ, Burrow MF. The effects of boric acid and phosphoric acid on the compressive strength of glassionomer cements. Dent Mater 2006;22(1):94-7.

[36] Ercan E, Çolak H, Hamidi MM, et al. Can Dentin surfaces be bonded safely with ozone and boric acid? Ozone: Science and Engineering 2015;37(6):556-62.

[37] Akturk E, Bektas 00, Ozkanoglu S, et al. Do ozonated water and boric acid affect the bond strength to dentin in different adhesive systems? Niger J Clin Pract 2019;22(12):1758-64.

[38] https://tr.wikipedia.org/wiki/Borik_asit\#Kaynak\%C3 \%a7a)

[39] Perdigão J, Gomes G, Lopes MM. Influence of conditioning time on enamel adhesion. Quintes Int 2006;37(1):35-41.

[40] Summitt JB, Robbins JW, Schwartz RS. Fundamentals of operative dentistry: a contemporary approach. $3^{\text {rd }}$ edn. ABD: Quintessence 2006.

[41] Bona AD, Van Noort R. Shear vs. tensile bond strength of resin composite bonded to ceramic. J Dent Res 1995;74(9):1591-6. 